Volume 13, número 2, Ano: 2017.

\title{
HOMOSSEXUALIDADE EM CENA: DA NATURALIDADE AO PRECONCEITO. REVISITANDO A PRODUÇÃO CIENTÍFICA NACIONAL
}

\author{
Diogo Fagundes Pereira ${ }^{1}$
}

\begin{abstract}
RESUMO Apresenta-se nesse estudo a história do comportamento homossexual desde a antiguidade até a legitimação do preconceito flagrante e seus resquícios sutis nos dias atuais. Além disso, esse estudo objetivou evidenciar a contribuição da Psicologia em relação aos estudos científicos no âmbito da homossexualidade no país. Para tanto, realizou-se uma revisão de literatura, com os descritores: Homossexualidade, Preconceito e Psicologia, nas bases de dados online: Capes, Scielo, Index Psi e Pepesic. Onde concluiu que apesar do fenômeno do preconceito ser amplamente estudado pela Psicologia Social, existe uma inexpressiva produção em relação ao estudo da homossexualidade dentro da ciência psicológica, o que sinaliza um reforço do preconceito destinado a esse grupo minoritário.
\end{abstract}

Palavras- Chave: Homossexualidade. Preconceito. Psicologia.

\section{HOMOSEXUALITY IN SCENE: THE BIRTH TO PREJUDICE. FACING THE NATIONAL SCIENTIFIC PRODUCTION}

\begin{abstract}
It is presented in this study the history of homosexual behavior from antiquity to the legitimacy of blatant prejudice and its subtle remnants today. In addition, this study aimed to highlight the contribution of psychology in relation to scientific studies in the context of homosexuality in the country. Therefore, we carried out a literature review, with the key words: Homosexuality, Prejudice and Psychology, in online databases: Capes, Scielo, Index Psi and Pepesic. Which concluded that despite the prejudice phenomenon being widely studied by social psychology, there is a negligible production in relation to the study of homosexuality within the psychological science, which signals a strengthening of prejudice aimed at this minority group..
\end{abstract}

Words- Key: Homosexuality. Prejudice. Psychology.

\footnotetext{
${ }^{1}$ Psicólogo, Pedagogo, Especialista em Neuropsicologia e Mestre em Psicologia. Coordenador Adjunto e Professor da Pós-Graduação em Avaliação Psicológica na Universidade Católica de Petrópolis.
} 


\section{ITHNERARIUS \\ REFLECTIONIS}

\section{Volume 13, número 2, Ano: 2017. 1 INTRODUÇÃO}

A prática sexual com uma pessoa do mesmo sexo, conhecido na modernidade como homossexualidade é um fenômeno tão antigo quanto comum na história da humanidade, porém, a interpretação de sua prática varia de acordo com o contexto histórico. Nesse sentido, esse estudo apresentou desde a naturalidade do fenômeno na Grécia Clássica à instalação e manutenção do preconceito nos dias atuais. Em seguida evidenciou em que contexto surge à palavra homossexual e o peso semântico desse verbete nas relações sociais. Assim articulou-se o dialogo entre o fenômeno do preconceito, pensado a partir da psicologia social com o processo histórico da homossexualidade, estigmatizado até nos dias atuais, tanto no âmbito social, como também, presente nos processos educativos de maneira geral.

\section{HOMOSSEXUALIDADE: DA GRÉCIA CLÁSSICA A MODERNIDADE}

A existência da prática sexual entre duas pessoas do mesmo sexo é tão antiga quanto à própria história da evolução do pensamento humano, independente do conceito vinculado a essa prática, ou seja, do nome que lhe é atribuído, o seu exercício já vem de longas datas. Mesmo reconhecendo a dificuldade de contar a história da homossexualidade, uma vez que esta sempre esteve nos bastidores da história oficial, de acordo com Ullman (2005), as práticas sexuais ocorridas no século VII A.C na Grécia Antiga entre duas pessoas do mesmo sexo, tinham função social e pedagógica. $O$ relacionamento sexual entre dois homens eram visto de maneiras diferentes entre as duas cidades gregas Esparta e Atenas.

Esparta, sociedade guerreira, os casais de homens era incentivados a manterem sua vida sexual entre eles, como parte do treinamento e da disciplina militar, sinalizando coesão e cuidado entre o grupo. Portanto, a prática além de não denotar inferioridade, trazia a noção de pertença e era bem visto no grupo. A cidade de Atenas destacava-se no campo do conhecimento, o grau de desenvolvimento político e condições privilegiadas da economia, foram fatores importantes para o seu florescimento intelectual. Portanto, à relação sexual entre dois homens eram aceita pela sociedade ateniense e se dava pelo relacionamento entre um homem mais velho, o erastes, e por um jovem a quem 


\section{ITINERARIUS REFLECTIONIS}

Volume 13, número 2, Ano: 2017.
REVISTAELETRÔNICA

DA GRADUAÇÃO/PÓS-GRADUAÇÃO EM EDUCAÇÃ O

ISSN. 1807-9342

chamavam de eromenos, que deveria ter mais de 12 e menos de 18 anos de idade, e esse relacionamento tinha era conhecido como paiderastia (amor a meninos) e tinha a função de transmissão de conhecimento, essa prática, portanto, era comum no processo da paidea, que era o paradigma da educação masculina.

As mulheres por sua vez, estavam destinadas apenas a função reprodutora, após gerar seus filhos estava terminada a sua função social, pois ela não possuía paidea e não poderia transmitir conhecimentos. Os meninos eram educados pelo Estado, e após isso, educados pelo erastes. Nessa relação apenas o erastes poderia demonstrar e sentir algum tipo de prazer, o eromenos por sua vez, era sempre o passivo e todo o processo começava com ganho de presentes até o menino aceitar o velho. Em relação aos atos sexuais, apenas o mais velho buscava satisfação pela masturbação ou na posição intrafemural. Quando o pupilo alcançasse a vida adulta ele procuraria seu eromenos e a antiga relação viraria somente amizade. A pederastia tinha status privilegiado, consistindo na passagem de um rapaz para a vida adulta, sendo uma forma elevada de educação e transmissão de valores aristocráticos de uma geração para a outra. A repressão e controle existiam não para aqueles que tinham relação sexual entre duas pessoas do mesmo sexo, mas para aqueles que mantinham comportamentos vinculados à feminilidade, não sendo viris.

Diversas são as falas de poetas e filósofos que fazem menção a esse "amor grego, amor pederástico". Faz-se necessário registrar a diferença da instituição pederastia da prática homossexual, uma tinha a função pedagógica e social que diverge totalmente do modelo da homossexualidade moderna, que é um tipo de relação afetiva. Na pederastia, os amantes deveriam seguir regras minuciosas de etiqueta para legitimar o papel social da relação e deixar longe qualquer dubiedade vinculada essa a prática. Porém, a compreensão histórica de algo que é de ordem do comportamento pode sugerir outras leituras e interpretações, por exemplo, nesse período, conforma aponta Ullman (2005) existia uma aversão sobre a renúncia dos traços viris e a relação entre duas pessoas do mesmo sexo não poderia ser de maneira desbragada, ao bel-prazer. Isso denota uma preocupação social de um envolvimento afetivo além dos fins pedagógico e coesão de grupo.

Outro aspecto que sinaliza a o premear do preconceito tem relação com a existência de alguns verbetes gregos que faziam alusão à homossexualidade (sexo sem 


\section{ITINERARIUS REFLECTIONIS}

Volume 13, número 2, Ano: 2017.
REVISTA ELETRÔNICA

DA GRADUAÇÃ O/PÓS - GRADUAÇÃO EM EDUCAÇÃ O

ISSN. 1807-9342

fins pedagógico) existiam as palavras: “bínein, katapygôn, euripróktos na sociedade grega e elas eram muito comuns" (ULLMAN, 2005 p.23), essas expressões sinalizavam a relação de uma maneira inferior, indigna, desprezível e desavergonhada. Ou seja, existiam espaços em que a pratica sexual entre dois homens não estavam ligadas diretamente a questões pedagógicas.

O amor grego muitas vezes interpretado como amor livre, não era tão livre, pois estava demarcado de papéis sociais bem definidos. A categorização que existia, não tinha relação com gênero, mas com poder. De um lado os homens adultos, livres, ativos em todos os sentidos e do outro as mulheres, crianças, rapazes e escravos. E nesse contexto político e de poder que se organizavam a dinâmica social da Grécia Clássica.

Contrapondo as condições sociais na qual a pederastia acontecia em relação à homossexualidade moderna, infere-se que a falta de contextualização histórica faz com que muitas vezes o homem não consiga compreender a construção dos comportamentos e a evolução do pensamento humano, os discursos, as posturas ou até os princípios éticos que são produtos de um contexto, resultando em generalizações superficiais ou mesmo frívolas de questões relacionadas à natureza humana. Nesse sentido, esse marco teórico apresentou uma "normalidade social" em relação pederastia, evidenciando a sua função e seu espaço dentro de uma sociedade. As inferências ao amor grego que comumente são feitas buscando correlacionar a homossexualidade moderna com a pederastia são incorretas e empobrecidas. Nesse sentido, surge a necessidade de trazer à luz a etimologia da palavra homossexual, para a partir dessa ideia, falar de outro tipo de relacionamento.

\section{CONCEITUAÇÃO DA PALAVRA HOMOSSEXUAL}

Do ponto de vista histórico, é um equivoco pensar na Grécia Antiga como o berço da homossexualidade, ou o seu "marco zero", pois não é possível precisar uma data que esse comportamento humano passou a existir. A existência da relação entre duas pessoas do mesmo sexo foi presente na Grécia Antiga, assim como em outros momentos históricos, mas essa relação não pode ser conceituada como uma relação homossexual, pois esse termo foi criado somente na modernidade. Nesse sentido, evidenciar o discurso da homossexualidade na modernidade, consequentemente o surgimento de sujeitos 


\section{ITINERARIUS REFLECTIONIS}

Volume 13, número 2, Ano: 2017.
REVISTA ELETRÔNICA

DA GRADUAÇÃO/PÓS-GRADUAÇÃO EM EDUCAÇÃ O

ISSN. 1807-9342

homossexuais e suas funções, é muito mais importante do que compreender a etiologia da sua prática. Não obstante, é válido salientar que dar créditos à modernidade pela conceitualização da homossexualidade não é a mesma coisa que dizer que esta inventou a prática sexual entre duas pessoas do mesmo sexo.

A homossexualidade como categoria identitária de construção do sujeito não se limita a simples descrição de suas práticas. Pois se assim fosse, a Grécia Clássica estaria repleto de homossexuais, principalmente nas classes mais abastadas, devido as suas práticas. E como discorrido anteriormente, a pederastia por mais que se assemelhasse, aos contatos homossexuais da modernidade, estão longe desse recorte, devido as suas funções sociais. Muito foi estudado e ainda é sobre a etiologia do comportamento homossexual, porém a questão aqui se direciona para a compreensão do conceito, de saber quem é o homossexual, qual o espaço e de que maneira essa relação está expressa ao longo dos tempos. Na busca de definir o que é o homossexual os Antropólogos Fry e McRae (1985) induzem a seguinte observação:

O problema é que a homossexualidade é uma infinita variação sobre um mesmo tema: o das relações sexuais e afetivas entre pessoas do mesmo sexo. Assim, ela é uma coisa na Grécia Antiga, outra coisa na Europa do fim do século XIX, outra coisa entre os Índios Guaiaqui do Paraguai. Com este raciocínio, a homossexualidade pode ser uma coisa para um camponês do Mato Grosso, outra coisa para o candidato a governador do Estado de São Paulo em 1982 e, de fato, tantas coisas quanto os diversos segmentos sociais da sociedade brasileira contemporânea (Fry \& Mcrae, 1985, p1).

O conceito da homossexualidade foi criado para designar um comportamento e delimitar um tipo de atuação. Se na ausência da definição, a prática sempre existiu enquanto fenômeno humano será que a definição construiu uma categoria? A visão da homossexualidade, homoerotismo ou a relação sexual entre duas pessoas do mesmo sexo varia ao longo da história e é diferente em cada uma das diversas culturas existentes. Em 1870 "os psiquiatras começaram a fazer da homossexualidade um objeto de análise médica" (FOUCAULT, 1979 p.541), nesse período os homossexuais eram internados em asilos para tratamento, eram vistos como loucos e libertinos sexuais, e nesse contexto, inegavelmente a literatura médica ganhava notoriedade e autoridade sobre o tema a ponto 


\section{ITINERARIUS REFLECTIONIS}

Volume 13, número 2, Ano: 2017.
REVISTAELETRÔNICA

DA GRADUAÇÃ O/PÓS - GRADUAÇÃO EM EDUCAÇÃ O

ISSN. 1807-9342

de criar crenças e influenciar a sociedade da época, onde às vezes, podem-se perceber vestígios dessas crenças ainda muito presente em discursos e produções científicas, ou até mesmo, refletidas na ausência dessas produções.

Vale destacar que segundo Brandão (2002), o termo "homossexual" foi utilizado pela primeira vez em 1869, por um médico belga Karl Maria Kertbeny, que na sua juventude tinha um amigo homossexual que se suicidou ao ser chantageado. Ele recordou mais tarde que esse episódio que o levou a interessar-se pelo tema da homossexualidade e de lutar pelas injustiças. Depois de um período no exército húngaro, empregou-se como jornalista e em 1847 alterou legalmente seu nome para Károly Mária Kertbeny, mudandose para Berlin, a partir de 1869 começou a publicar anonimamente alguns panfletos vinculados à temática da homossexualidade, quando ainda nesse ano criou a palavra "homossexual" como parte dos seus sistemas de classificações de tipos sexuais, substituindo o termo pederastia.

Essa prática "sem nome” é então nominada, demarcada e patologizada. Como se o homossexual que acaba de ser produzido, seja aquele sujeito que vive a sua sexualidade em todos os poros, de maneira intensa, que esse título, essa condição assume as rédeas da vida, assume a conduta, a fala, os sonhos e por ser diferente do que é esperado, por ter perdido a função de coesão de grupo ou de transmissão de conhecimento, tornando-se uma prática livre do sexo pelo prazer, sem fins justificáveis e regras claras, desvia-se da norma, e patologiza-se o fenômeno e prática sexual entre duas pessoas do mesmo sexo. A homossexualidade é, portanto, a categorização daquele sujeito que sente desejo e atração por outro do mesmo sexo.

De acordo com Peter Fry (1985), em 1886, o sexólogo Richard Von KrafftEbing, listou a homossexualidade e outros 200 estudos de casos de práticas sexuais em sua obra Psychopathia Sexualis, ele propôs que a homossexualidade era causada por uma "inversão congênita" que ocorria durante o nascimento ou era adquirida pelo indivíduo. Esse médico coletou milhares de "confissões" dos seus pacientes influenciando a medicina definitivamente.

Em 1952 a Associação Americana de Psiquiatria publicou em seu primeiro Manual Diagnóstico e Estatístico dos Transtornos Mentais, a homossexualidade como uma desordem mental. Conforme Guimarães (2013) em 1977 a Organização Mundial de 
Volume 13, número 2, Ano: 2017.

Saúde (OMS) inclui o homossexualismo na Classificação Internacional de Doenças (CID) mais uma vez como doença mental, sendo retirada em 1990. O Conselho Federal de Psicologia, considerando que a homossexualidade não constitui doença, nem distúrbio e nem perversão em março de 1999 resolve em seu artigo $3^{\circ}$ e $4^{\circ}$ :

Art. $3^{\circ}$ - os psicólogos não exercerão qualquer ação que favoreça a patologização de comportamentos ou práticas homoeróticas, nem adotarão ação coercitiva tendente a orientar homossexuais para tratamentos não solicitados. Parágrafo único - Os psicólogos não colaborarão com eventos e serviços que proponham tratamento e cura das homossexualidades.

Art. $4^{\circ}$ - Os psicólogos não se pronunciarão, nem participarão de pronunciamentos públicos, nos meios de comunicação de massa, de modo a reforçar os preconceitos sociais existentes em relação aos homossexuais como portadores de qualquer desordem psíquica. (CFP, 1999, para 3 e 4).

A prática sexual entre duas pessoas do mesmo sexo teve historicamente um viés social, pedagógico e político, não abriu a possibilidade de que esses encontros pudessem ser mais que meramente dois corpos com objetivos previamente definidos, negando inúmeras demandas psicológicas e afetivas que aconteciam durante todo esse processo, estimulando um "mutismo social" em relação às condutas homossexuais que acontecia mesmo que à revelia das expectativas da época. E já reconhecendo o espaço da clandestinidade para dar vasão aos desejos pessoais é que de uma maneira sutil inicia-se o preconceito destinado ao grupo dos homossexuais.

Conforme Nunan (2003), quando Alfred Kinsey publicou seu estudo clássico Sexual Behavior in the Humam Male, ele evidencia que os humanos variam sexualmente de uma maneira inclassificável, e que a diversificação é uma característica comum na natureza humana e não um desvio da norma. Portanto, a maneira como os seres humanos são classificados em algum aspecto não retratam a sua essência em si, mas apenas um resultado de uma construção histórica.

Nenhuma classificação aplicada ao ser humano funciona fora do seu contexto histórico, por isso qualquer termo que vincule a homossexualidade à prática sexual na Grécia Antiga é leviana. Por mais que exista semelhança nas práticas e demandas psicológicas e afetivas geradas, a ideia de homossexualidade é datada e ela advém a partir de outro conceito também moderno que é a sexualidade. Falar de sexualidade em qualquer aspecto pode ser um terreno extremamente escorregadio, e explicar o comportamento 


\section{ITHNERARIUS REFLECTIONIS}

Volume 13, número 2, Ano: 2017.
REVISTA ELETRÔNICA

DA GRADUAÇÃ O/PÓS - GRADUAÇÃO EM EDUCAÇÃ O

ISSN. 1807-9342

humano através da sua orientação sexual é empobrecedor, pois a subjetividade humana não pode ser reduzida a uma "identidade" que não o define, mas apenas classifica e reduz.

\section{A FISIONOMIA DO PRECONCEITO HOMOSSEXUAL}

Falar sobre a classificação automaticamente traz a tona o fenômeno do preconceito. O preconceito visto enquanto resultado de um processo de categorização que pode derivar a estereotipia ou discriminação está presente na sociedade desde a Antiguidade, porém até meados do século XX era tido como algo natural e justificado socialmente através da inferioridade de determinados grupos (Fernandes, Da Costa, Camino \& Mendonza, 2007; Lima \& Vala, 2004).

O preconceito entendido como um constructo científico autônomo começou a ser estudado atentamente por psicólogos segundo Duckitt (1992) na década de 20 e esse mesmo autor evidencia que ao longo do século XX, houve diversas teorias que estudaram o preconceito. Gordon Allport, psicólogo norte americano publicou seu clássico em 1954 The Nature of Prejudice. Sendo um dos pioneiros no estudo dessa temática, para ele, o preconceito é "uma atitude hostil ou preventiva a uma pessoa que pertence a um grupo, simplesmente porque pertence a esse grupo, supondo-se, portanto, que possui as características contestáveis a esse grupo" (Allport, 1954 p. 22). Nesse sentido a hostilidade seria uma característica aprendida e que pode assumir cinco graus de expressão conforme a sua escala de Preconceito e discriminação.

Em outra perspectiva, surge Theodor W. Adorno (1965), filósofo alemão, realizou um estudo buscando compreender os elementos que compõe o preconceito do ser humano. Ele partiu da premissa que a adesão a uma determinada ideologia poderia estar fundamentada em questões psíquicas e não necessariamente racionais. Nesse estudo Adorno et al. (1965) estabeleceu constituições de indivíduos que seriam predispostos ao preconceito e outros que não. Os predispostos seriam os ressentidos superficial, convencional, autoritário, rebelde e psicopata, lunático e manipulador. Já os indivíduos que não apresentaram disposição elevadas ao preconceito são dos tipos: rígido, protestador, impulsivo, despreocupado e liberal genuíno. Logo Adorno, trás contribuições 


\section{ITINERARIUS REFLECTIONIS}

Volume 13, número 2, Ano: 2017.
REVISTA ELETRÔNICA

DA GRADUAÇÃ O/PÓS - GRADUAÇÃO EM EDUCAÇÃ O

ISSN. 1807-9342

das características da personalidade como elementos fundamentais na formação do preconceito.

Crochik (1997) acrescenta que ainda tem as questões culturais que atravessam o processo da constituição do preconceito. O simples fato de ter que preparar os filhos para um mundo competitivo e sem perspectiva, tem de certa maneira, sobrepujado o ideal de sobrevivência a outros valores sociais. Portanto, para viver com menos conflitos, ou mesmo para adaptar as estruturas de personalidade ao mundo moderno, o sujeito desenvolve uma insensibilidade em relação ao outro. Outro aspecto é a generalização das características de um determinado grupo para todos os indivíduos que pertencem a ele. Suas relações seguem através de categorizações que classificam os sujeitos o que impede que experiência individual se contraponha ao estereótipo.

Snowden (1995), em uma análise histórica do preconceito, afirma que já existia preconceito na antiguidade greco-romana, evidente que esse preconceito não era racial nem sexual, porque as divisões dos grupos não estavam vinculadas a esses critérios, e sim a uma base cultural, existia um preconceito contra os escravos, que na maior parte das vezes eram brancos. Portanto, infere-se que a lógica do preconceito tem relação direta com a maneira que os grupos são definidos na sociedade e qual o seu papel na hierarquia social. Evidentemente o preconceito em relação aos homossexuais só é demarcado, quando esse grupo passa ser definido, pois quando a sexualidade não era foco, nem divisão de grupo, não poderia ocupar nenhum papel de importância na matriz social.

Pettigrew \& Meertens (1995), verificou o preconceito racial na Europa, e extraiu desse estudo duas categorias independentes do público alvo: o preconceito flagrante e a sutil, a primeira é a forma mais tradicional de expressão, sendo ela de maneira direta e aberta, o próprio Allport (1954), falava dessa forma de preconceito, enquanto a segunda, a sutil, é discreta e indireta, dessa forma além de preservar a expressão do preconceito atende a forma da não discriminação, uma vez que preconceito no Brasil é crime.

Nesse sentido, percebe-se que muito tem estudado e pesquisado sobre o preconceito nos últimos anos, é comum notar o discurso que o preconceito, seja ele qual for, tem que ser combatido. Porém, a possibilidade de combate não é sinônima de inexistência. Ele passa a ser justificado e essa modalidade "sutil" ainda não é admitida como preconceito. Essa sutileza ainda é difícil de ser claramente percebida, mas dada as 


\section{ITINERARIUS REFLECTIONIS}

Volume 13, número 2, Ano: 2017.
REVISTA ELETRÔNICA

DA GRADUAÇÃO/PÓS-GRADUAÇÃO EM EDUCAÇÃ O

ISSN. 1807-9342

condições adequadas para a expressão do preconceito, ele se manifesta declaradamente.

No tocante da homossexualidade, sabendo que a orientação sexual de qualquer pessoa não a afasta de suas competências, habilidades, responsabilidade e deveres morais e éticos, mesmo assim, os indivíduos que apresentam traços que o identificam com o grupo de homossexualidade, sofrem retaliações em muitas áreas sociais, como a impossibilidade do exercício de magistério nas classes iniciais, do exercício do poder de polícia, entre tantas outras oportunidades laborais que lhe são retiradas, pelo simples fato de pertencer a um grupo de orientação sexual divergente da majoritária. Isso sem levar em consideração todos os conflitos psicológicos que são enfrentados ainda hoje aos sujeitos pertencentes a esse grupo. Nesse sentido, é valido salientar a necessidade de a Psicologia Social ficar atenta a esses matizes de preconceito que ainda perpetua na sociedade moderna, mesmo que de uma maneira velada, mas que reproduz um sistema de exclusão e discriminação, sendo necessário conhecer ainda mais os elementos que compõe essa nova fisionomia de preconceito, de maneira a evidenciar a manifestação e exercício, em busca de uma qualidade e equidade entre as relações interpessoais. Devolvendo historicamente os danos causados a esses grupos, bem como, construindo uma sociedade de oportunidades mais justas e igualitárias.

Partindo do pressuposto que a homossexualidade segundo Foucault (1984), é uma construção sócio histórica, pode-se inferir que o preconceito direcionado a esse grupo também é uma construção sócio histórica, ou seja, esse preconceito foi datado. A partir do momento que o indivíduo através de sua manifestação sexual ocupa um lugar diferente na sociedade, mesmo que seja um lugar de invisibilidade, o preconceito se instala e legitima essa diferenciação entre os grupos por conta de suas diferenças sexuais.

O preconceito social no Brasil pode ser entendido como um dos importantes mecanismos da manutenção da hierarquização entre grupos sociais e da legitimação da inferiorização social na história de uma sociedade, o que muitas vezes consolida-se como violência e ódio um com os outros. (Prado \& Machado, 2012 pg 67).

Vários estudos sobre o preconceito tem demonstrado a conexão entre a relação de inferiorização e mecanismos de naturalização das desigualdades históricas (Adorno e Horkheimer, 1973; Crochik, 1997; Camino 2002). E nesse sentido é importante compreender a lógica do funcionamento do preconceito e de que maneira ele vem sendo 


\section{ITHNERARIUS REFLECTIONIS}

Volume 13, número 2, Ano: 2017.

mantido ao longo dos anos em relação aos homossexuais e como que ele reforça a homofobia. Segundo Prado (2012), existe a crença que algumas relações sociais são e devem ser hierarquizada para manutenção e equilíbrio da sociedade. Relações como chefe / subordinado, gerente / subgerente e professor / aluno, são relações normais, sadias e essa hierarquização é necessária para a ordem social, esta é uma lógica historicamente construída e pelo fato de ser histórico vem se retroalimentando ao longo dos anos, naturalizando-se. Porem é nesse jogo entre hierarquização e inferiorizações que o preconceito social atua e é utilizado para os processos de dominância social.

De posse desse pressuposto, uma vez que a homossexualidade, a partir de um dado momento histórico é colocada em uma posição hierárquica inferior à heterossexualidade, o preconceito social produz contra esse grupo, uma espécie de invisibilidade, mesmo sabendo da existência da prática da homossexualidade, logo da existência dos homossexuais, é necessário tornar essa dinâmica invisível, clandestina, pois assim, não subverte valores históricos e garante a ordem social. A negação da existência desse grupo, mesmo a negação de seus direitos, bem como, a inferiorização social dos homossexuais, cria o efeito secundário da homofobia.

A homofobia é um neologismo cunhado pelo psicólogo George Weinberg (1972), que uniu dois radicais gregos que significam (semelhante e medo) para designar sentimentos negativos em relação aos homossexuais ou mesmo a própria homossexualidade. É uma palavra polissêmica, que vem assumindo diversos significados a depender da área de conhecimento que está sendo utilizada, perdendo com o passar dos anos, a vinculação direta ao termo "fobia". Klecius Borges (2009) define em seu livro "Terapia Afirmativa" três dimensões da homofobia: A social e cultural, institucionalizada e a internalizada. A primeira apoia-se na crença que a homossexualidade ameaça a estrutura social patriarcal, onde os valores masculinos predominam e nesse sentido o homossexual é associado à figura feminina, logo considerado inferior na escala social. A segunda, parte da ideia que todos são heterossexuais, e a última a homofobia internalizada, traz questões mais elementares dos prejuízos na saúde psíquica, pois aponta que desde criança o homossexual internaliza mensagens negativas em relação a essa expressão e quando se depara com a sua sexualidade nesse campo podendo na maior parte das vezes, expressar insatisfação com a sua orientação sexual, mesmo quando esses 


\section{ITHERARIUS REFLECTIONIS}

Volume 13, número 2, Ano: 2017.
REVISTA ELETRÔNICA

DA GRADUAÇÃ O/PÓS - GRADUAÇÃO EM EDUCAÇÃ O

ISSN. 1807-9342

sentimentos não estão perceptíveis à consciência. A exposição contínua à homofobia social e cultural torna-o predisposto a criar defesas psicológicas e adaptação ao meio, essa exposição pode influenciar a sua autoestima como também outros comportamentos vinculados à sua personalidade. Como também estão mais predispostos a se sentir diferentes do demais, e essa diferença esta associada à inferioridade, tem uma auto percepção empobrecida, fruto da exposição da dinâmica do preconceito e sentem-se em alguns momentos culpados e envergonhados por serem diferente da média, e para aqueles que o auto reconhecimento da sua condição não é possível ainda tem que viver em dois mundos simultaneamente.

Nesse sentido, Prado (2012) comenta que os homossexuais em um processo de simplificação de suas vidas, acabam assimilando valores culturais dominantes, reproduzindo a suposta coerência das práticas sociais para minimizar os possíveis danos que o comportamento contrário poderia acontecer. Essa postura reforça ainda mais a legitimação da ordem social, contribuindo para que a prática da discriminalização e inferiorização não seja interpretada como injusta, mantendo sua opressão de maneira invisível, como se essa dinâmica fosse um processo natural, ou seja, que a lógica da subordinação seja considerada natural entre alguns grupos, e que o homossexual saiba que as suas práticas é que são subversivas e disfuncionais.

Esse raciocínio é fundamental para a conceituação da homossexualidade como uma não heterossexualidade, pois no momento que estabelece o comportamento heterossexual como norma, qualquer comportamento diferente é desviante, gerando a sensação da "cidadania subalterna". Isso porque a homossexualidade tem uma relação conflituosa entre a experiência privada e a pública. Ela é vivida nas relações privadas e é omitido nas relações públicas, o que enfraquece seu reconhecimento como condição natural das experiências humanas. Assim, no espaço público a identidade homossexual acaba se fragilizando, pois instituições sociais - escola e família, entre outras - formam estratégias de "controle da sexualidade", que causam uma invisibilidade da homossexualidade.

\section{METODOLOGIA}




\section{ITHERARHUS REFLECTIONIS}

REVISTA ELETRÔNICA

DA GRADUAÇÃO/PÓS - GRADUAÇÃO EM EDUCAÇÃ O

\section{Volume 13, número 2, Ano: 2017.}

Trata-se de uma revisão sistemática da literatura em que foram utilizadas as bases de dados online Pepsic, Scielo, Index Psi Teses e Index Psi Periódicos-Científicos e Periódicos Capes, com os descritores: Homossexualidade, psicologia, preconceito. A partir desse referencial foram feitas as revisões sobre a temática no Brasil, excluindo toda a literatura mesmo que tenha referência com a homossexualidade, mas que não faça conexão direta com todos os descritores.

O material discursivo foi lido/refletido na íntegra, de modo a extrair as convergências, divergências e novas perspectivas acerca do tema abordado. A partir da leitura exaustiva dos trabalhos, dois tipos de análises foram realizadas: uma análise quantitativa e outra qualitativa. A primeira, de natureza quantitativa, objetivou traçar um perfil da produção bibliográfica, em relação à quantidade de trabalhos publicados, ano de publicação, região predominante dos pesquisadores, tipos de produção (teórica $\mathrm{x}$ empírica) e método de pesquisa utilizado. A segunda de cunho qualitativo, foi realizada uma categorização dos conteúdos, para melhorar a análise dos dados, as categorias foram: Vivência em relação ao preconceito; Discurso Psicológico em relação a Homossexualidade; Construção da identidade Homossexual; Adoção homossexual; Preconceito Homossexual; Percepção da homossexualidade.

\section{RESULTADOS}

Em termos quantitativos foram encontrados 23 trabalhos, incluindo artigos (20), dissertação (1) e teses (2), distribuídas ao longo de 13 anos (2002 - 2015): 2002 (2), 2006 (2), 2007 (4), 2009 (1), 2011 (1), 2012 (4), 2013 (5), 2014 (1), 2015 (3). Quando foi avaliado o vínculo institucional do primeiro autor, evidenciou que os trabalhos são produzidos por pesquisadores do Centro Oeste (4), Nordeste (4), Sudeste (8), Sul (2) e Portugal (4). Em relação ao tipo da pesquisa, foram qualitativas (8) e quantitativas (15).

Em termos qualitativos, após analisar o conteúdo dos textos, foram elencadas seis categorias temáticas para facilitar a análise dos dados, sendo elas: Vivência em relação ao preconceito (2), Discurso Psicológico em relação a Homossexualidade (2), Construção da identidade Homossexual (2), Adoção homossexual (5), Preconceito Homossexual (9) e percepção da homossexualidade (3). 


\section{ITHNERARHUS REFLECTIONIS}

Volume 13, número 2, Ano: 2017.
REVISTAELETRÔNICA

DA GRADUAÇÃ O/PÓS-GRADUAÇÃO EM EDUCAÇÃ O

ISSN. 1807-9342

\section{ANÁLISE DOS DADOS}

Do ponto de vista quantitativo percebe-se que em um largo espaço de tempo (13 anos) a produção científica da psicologia em relação à homossexualidade ainda é muito inexpressiva, em relação a outras temáticas estudadas pela psicologia nesse período, e principalmente a má distribuição dos pesquisadores que se envolveram com essa temática, estando concentrada a maior parte dos trabalhos, na região sudeste do país.

Em relação às categorias de análise quantitativas anteriormente descritas, estudos mostraram a atitude de evitação em relação à exposição da orientação sexual do sujeito, a fim de não gerar situações constrangedoras e perdas de empregos (Madureira \& Branco, 2007; Cechin, 2006; Costa \& Machado, 2015). Outras pesquisas evidenciaram a necessidade de fomento de mecanismos psicossociais e jurídicos que contribuam para o esclarecimento da questão da adoção por casais homossexuais, visto o preconceito e a ideia de desenvolvimento de prejuízos psicológicos nas crianças, valorizando um discurso de criação de distúrbios psicológicos em detrimento a adoção (Araújo et al, 2007; Oliveira, 2012; Pereira \& Torres, 2012; Cerqueira, 2015).

Estudos apontaram o preconceito contra homossexuais se expressa de maneira mais sutil do que flagrante, apresentando maiores características positivas em relação ao grupo majoritário, os heterossexuais (Fleury \& Torres, 2007; Gato \& Leme, 2014; Gouveia \& Soares, 2012; Lima \& Eddine, 2015).

Pesquisas também revelam o auto preconceito, homofobia internalizada e ocultação da orientação sexual, por medo de retaliações sociais (Madureira \& Branco, Rabelo, 2013).

Lima \& Eddine (2015), mostraram como o tema "homossexualidade" ainda é escasso na literatura psicológica, demonstrando a necessidade da psicologia se debruçar mais sobre essa temática.

E finalmente Costa et al (2015) aponta que o preconceito contra homossexuais encontra-se concentrado em alguns espaços sociais, principalmente trabalho e família. 


\section{ITHNERARHUS \\ REFLECTIONIS}

\section{Volume 13, número 2, Ano: 2017. 8 CONSIDERAÇÕES FINAIS}

Apesar de toda evidência histórica demonstrada no inicio desse artigo, onde a relação afetiva- sexual entre duas pessoas do mesmo sexo existia de maneira natural, pedagógica e estratégica, a partir do momento que esse fenômeno foi patologizado, a prática da homossexualidade tornou-se um fenômeno inferiorizado na sociedade. Mesmo após a "alforria" do status de doença, a herança negativa histórica ainda ressoa e permeia os indivíduos, a ponto de estudos citados, evidenciaram um numero estatisticamente significativo em relação à quantidade de sujeitos homossexuais, que precisam adotar um estereótipo de heterossexualidade, para comungar dos mesmos direitos do grupo dominante. Demonstrando que essa ocultação de suas práticas coaduna com a manifestação do preconceito sutil que ainda impera na sociedade vigente. Além das questões jurídicas, de direito de família, adoção e bens, ainda ser um grande problema social e gerar muita controversa, o respeito a esse publico, a esse grupo social ainda é muito temeroso.

A escassez de produções científica na psicologia em relação à homossexualidade pode evidenciar um preconceito que reside nos bastidores de uma sociedade de ideias majoritariamente branca e heterossexual, pois é preciso do ponto de vista científico avançar no sentido de não acreditar na existência de um único modelo de fazer ciência, de família, de cor e gênero, pois esse projeto de unicidade na história, é um projeto fascista e catastrófico. O preconceito enquanto atitude hostil em relação a um grupo precisa ser extinto, assim como, o preconceito acadêmico em não poder produzir, ou produzir timidamente em relação à homossexualidade precisa também acabar. É imperativo reconhecer a singularidade do ser humano, e começar a compreender que o enriquecedor na vida é a diversidade.

Nesse sentido é preciso que a psicologia se debruce e se aproprie dessa temática evidenciando essa dinâmica cruel da manutenção do preconceito contra homossexuais, no sentido de desmistificar, de desvelar essa sensação histórica de que a inferiorização de alguns grupos na sociedade é importante para manutenção da ordem social, pois esse raciocínio esconde uma lógica perversa, que não é natural e sim histórica, ou seja, foi datada e criada em um determinado momento, para servir a um determinado grupo em detrimento de outros. Acarretando prejuízo ao grupo oprimido, que no caso analisado é o 


\section{ITINERARHS REFLECTIONIS}

REVISTAELETRÔNICA

DA GRADUAÇ Ã O/PÓS - GRADUAÇÃ O EM E DUCAÇ Ã O

ISSN. 1807-9342

Volume 13, número 2, Ano: 2017.

dos homossexuais, forçando-o a desenvolverem habilidades psicológicas para uma possível adaptação ao mundo "naturalizado" do preconceito. Mesmo sob custo de comprometerem a sua saúde mental. Assim, é necessário compreender de que maneira essa lógica do preconceito foi estabelecida e de que maneira a Psicologia pode contribuir para minimizar e ressarcir os prejuízos destinados a esse grupo, bem como, a psicologia de maneira geral, identificar os mecanismos de resistência que estão presente nesse contexto, a fim de possibilitar uma saúde mental mais equitativa a todos os sujeitos, independente de suas orientações sexuais.

\section{REFERÊNCIAS}

ABREU, F. S. D. D., SILVA, D. N. H., \& ZUCHIWSCHI, J. (2015). Surdos e homossexuais: a (des) cobertade trajetórias silenciadas. Temas em Psicologia, 2015. ADORNO, T.W; FRENKEL- BRUNSWIK, E;LEVINSON, D.J e SANFORD, R.N. La Personalidade Autoritária. Buenos Aires, Editorial Proyéccion, 1965.

ALLPORT, G.W. (1954). La natureza del prejuicio. Buenos Aires: Ed Universitária, 1954.

AMERICAN PSYCHIATRIC ASSOCIATION . Diagnostic and Statistical Manual Mental Disorders. Washington. Ed. Ática, 1952.

AMERICAN PSYCHIATRY ASSOCIATION . Manual Diagnóstico e Estatístico de Transtornos Mentais - 5 $5^{\mathrm{a}}$ edição. Porto Alegre : Ed. Artmed, 2014.

ARAujO, L. D., OliveIRA, J. D., SOUSA, V. D., \& Castanha, A. R. Adoção de crianças por casais homoafetivos: um estudo comparativo entre universitários de Direito e de Psicologia. Rev Psicologia \& Sociedade, 19(2), 95-102, 2007.

BORGES, K. Terapia Afirmativa. São Paulo: Edições GLS.

CEARÁ, A. D. T., \& DALGALARRONDO, P. Transtornos mentais, qualidade de vida e identidade em homossexuais na maturidade e velhice. Revista de Psiquiatria Clínica, 37(3), 118-123, 2010.

CECHIN, A. F. Vivências em espaços educativos: constituição de identidades homossexuais em homens adultos. (Doctoral dissertation, Pontifícia Universidade Católica do Rio Grande do Sul), 2006. 


\section{ITINERARIUS REFLECTIONIS}

REVISTAELETRÔNICA

DA GRADUAÇÃ O/PÓS - GRADUAÇÃ O EM EDUCAÇ Ã O

Volume 13, número 2, Ano: 2017.

CERQUEIRA, E., \& SANTANA, G. Adoção homoparental e preconceito: crenças de estudantes de direito e serviço social. Temas em Psicologia, 23(4), 873-885. 2015.

CONSELHO FEDERAL E PSICOLOGIA. Legislação. Sobre gênero e sexualidade. Disponível em < http.//relacoesraciais.cfp.org.br/?p=13>. Acesso em 01 de nov. 2015.

CORCHIK, J.L . A personalidade narcisista segundo a Escola de Frankfurt e a ideologia da racionalidade tecnológica. Psicologia, 1 (2), 141 - 154, 1990.

COSTA, C. B. D, MACHADO, M. R., \& WAGNER, M. F. Percepções do homossexual masculino: sociedade, família e amizades. Temas em Psicologia, 23(3), 777-788, 2015.

COSTA. J.F. A Face e o Verso: Estudos sobre o Homoerotismo II. São Paulo: Escuta, 1995.

DUCKITT, J. Psychology and prejudice : a historical analysis and integrative framework. American Psychologist, 47 (10) 1182- 1183, 1992.

FERNANDES, S.C.S., DA COSTA, J.B.; CAMINO, L., \& MENDONZA, R. Orientação a Dominância Social - estudo empírico sobre preconceito emu ma amostra de estudantes universitários do curso de psicologia da cidade de João Pessoa. Cadernos de Psicologia - UFS, 3, 135-149, 2006.

FLEURY, A. R. D \& TORRES, A. R. R. (2007). Análise psicossocial do preconceito contra homossexuais. Estud. psicol.(Campinas), 24(4), 475-486, 2007.

FOUCAULT, M. História da Sexualidade I: a vontade de saber. Rio de Janeiro: Graal, 1984.

FRY, P; MACRAE, E. O que é homossexualidade. São Paulo: Editora Brasiliense, 1983. GATO, J. FONTAINE, A. M, \& LEME, V. B. Validação e adaptação transcultural da Escala Multidimensional de Atitudes Face a Lésbicas e a Gays. Psicologia: Reflexão e Crítica, 27(2), 257-271, 2014.

GONZAGA, L. L. DA SILVEIRA PRAÇA, A. V., \& LANNES, D. R. C. As representações sociais acerca de GAY entre estudantes da periferia do Rio de Janeiro. Revista Internacional Interdisciplinar INTERthesis, 11(2), 162-182, 2014.

GOUVEIA, V. V., ATHAUDE, R. A. A., SOARES, A. K. S., ARAÚJO, R. D. C. R., \& DE ANDRADE, J. M. (2012). Valores e motivações para responder sem preconceito frente a homossexuais. Psicologia em Estudo, 17(2), 215-225, 2012.

LACERDA, M., PEREIRA, C., \& CAMINO, L. Um estudo sobre as formas de preconceito contra homossexuais na perspectiva das representações sociais. Psicologia: reflexão e crítica, 15(1), 165-178, 2002. 


\section{ITHERARIUS REFLECTIONIS}

REVISTAELETRÔNICA

DA GRADUAÇÃ O/PÓS - GRADUAÇÃ O EM E DUCAÇ Ã O

Volume 13, número 2, Ano: 2017.

LIMA, M. D. F. E. M., \& EDDINE, E. A. C. Homossexualidades: espaço em uma revista especializada? Temas em Psicologia, 23(3), 789-801, 2015.

MADUREIRA, A. F. D. A., \& BRANCO, A. U. (2007). Identidades sexuais nãohegemônicas: processos identitários e estratégias para lidar com o preconceito. Revista Temas em Psicologia, 2007.

MOTT, L. Lesbianismo no Brasil. Porto Alegre: Mercado Aberto, 1987.

NUNAN, A. Homossexualidade: do preconceito aos padrões de consumo. Rio de Janeiro: Caravansarai, 2003.

OLIVEIRA, A. C. D. "Bons pais": representações e significações de pais hétero e homossexuais. Revista Educaçao, 2012.

PEREIRA, A. S. L. S., ALFAIA, A. J. B., SOUZA, L. E. C., \& LIMA, T. J. S. Preconceito contra homossexuais no contexto do futebol. Revista Psicologia \& Sociedade, 26(3), 2014.

PEREIRA, C. R., TORRES, A. R. R., FALCÃO, L., \& PEREIRA, A. S. O papel de representações sociais sobre a natureza da homossexualidade na oposição ao casamento civil e à adoção por famílias homoafetivas. Psicologia: Teoria $e$ Pesquisa, 29(1), 79-89, 2013.

PEREIRA, C. R., TORRES, A. R. R., PEREIRA, A., \& FALCÃO, L. Preconceito contra homossexuais e representações sociais da homossexualidade em seminaristas católicos e evangélicos. Psicologia: Teoria e Pesquisa, 27(1), 73-82, 2011.

PRADO, M.A.M.; MACHADO, F.V. Preconceito contra homossexualidades a hierarquia da invisibilidade. São Paulo: Cortez editora 2012.

Rabelo, A. A., \& Do NASCIMENTO, A. R. A. Vivência do preconceito e construção da identidade para homens homoafetivos/Experiences of prejudice and identity construction for homosexual men. Psicologia e Saber Social, 2(1), 131-141, 2013.

SILVA, V. G. D. A visibilidade do suposto passivo: uma atitude revolucionária do homossexual masculino. Revista Mal Estar e Subjetividade, 7(1), 71-88, 2007.

SNOWDEN Jr., F. M. Europe's oldest chapter in the history of black-white relations. In B. P. Bowser (Org), Racism and anti-racism in world perspective (pp.3-26) Londres: Sage, 1995.

UllmanN, R. A. Amor e sexo na Grécia Antiga. Porto Alegre: Edipucrs, 2005.

VON SMIGAY, K. E. Sexismo, homofobia e outras expressões correlatas de violência: desafios para a psicologia política. Psicologia em Revista, 8(11), 32-46, 2008. 


\section{ITINERARIUS REFLECTIONIS}

REVISTA ELETRÔNICA

DA GRADUAÇÃO/PÓS-GRADUAÇÃO EM EDUCAÇÃO

Volume 13, número 2, Ano: 2017.

ISSN. 1807-9342 